\title{
Administrative Claims Analysis of the Relationship Between Warfarin Use and Risk of Hemorrhage Including Drug-Drug and Drug-Disease Interactions
}

\author{
KUI ZHANG, MD; CHRISTOPHER YOUNG, PhD; and JAN BERGER, MD
}

\begin{abstract}
BACKGROUND: Despite the risk of hemorrhage, warfarin is the most commonly used oral anticoagulant today, both as monotherapy and when taken in combination with selected drugs. Warfarin is used most commonly for irregular heartbeat, after a heart attack, and after joint or heart valve replacement surgery.
\end{abstract}

OBJECTIVE: To evaluate the relative risk of hemorrhage in health plan members who received warfarin concomitant with a drug known to cause an interaction or after diagnosis of liver disease or heart failure (HF).

METHODS: A cohort study sample was drawn from an administrative database comprising medical and pharmacy claims for 1.7 million health plan members. A health plan member was defined as anyone who was eligible for pharmacy and medical benefits at any time from 0ctober 1, 2003, to September 30, 2004. To be included in the study, a member must have received at least 1 pharmacy claim for warfarin during the study period and been younger than 100 years.

Hemorrhage was defined as a diagnosed bleeding episode recorded on a medical claim within 7 calendar days of a fill date for a pharmacy claim (new or refill) for warfarin. The following variables were used to predict the outcome measures: type of drug-drug or drug-disease interaction, patient age and gender, number of unique prescribers during the year for all drugs, specialty of the first prescriber for warfarin, average dose of warfarin, and days of warfarin therapy. Because individuals were followed only during the calendar year under study, the authors have interpreted the days of therapy measured primarily as a control on exposure. The outcome measures are prevalence of drug and disease interactions among members receiving warfarin therapy and the per-patient-per-year and per-member-per-month (PMPM) cost of medical treatment of hemorrhage associated with warfarin therapy including drug and disease interactions. Costs are defined as the total paid amount for a procedure or service after negotiated provider discounts and subtraction of patient copay and deductibles. Logistic regression was used to evaluate the relative risk of hemorrhage in users of warfarin monotherapy and of warfarin users with drug-drug and drug-disease interactions. The comparison group in the logistic regression comprised the members who were not diagnosed with either HF or liver disease and who received warfarin therapy but none of the drugs under study known to cause drug interactions. Therefore, the odds ratios [ORs] produced were estimates of the relative risk of hemorrhage when taking warfarin concomitant with selected drugs and diseases.

RESULTS: Of the 17,895 patients who used warfarin during the study year, 2,634 (14.7\%) were diagnosed with a hemorrhage event within 1 week after filling a prescription for warfarin. The factors associated with an increased risk of hemorrhage included female gender (OR 1.149; 95\% confidence interval [Cl], 1.0531.253), liver disease (OR 1.764; $95 \% \mathrm{Cl}, 1.360-2.288$ ), and $\mathrm{HF}$ (OR 1.559; $95 \% \mathrm{Cl}$, 1.373-1.770). Compared with the use of warfarin alone, the use of either cephalosporins (OR 1.157; 95\% Cl, 1.043-1.285) or metronidazole (OR 1.578; 95\% $\mathrm{Cl}, 1.321-1.886)$ was associated with increased risk of hemorrhage, whereas the risk of hemorrhage was not greater for concomitant use of warfarin with amiodarone, fibric acid derivatives, or nonsteroidal anti-inflammatory drugs (NSAIDs), including cyclooxygenase-2 (COX-2) inhibitors. There was no relationship between estimated average daily warfarin dose and prevalence of hemorrhage. Other variables associated with an increased risk of hemorrhage were increased patient age, female gender, 120 days or more of warfarin therapy during the year, 2 or more unique prescriber numbers, and the medical specialty of the first prescriber of warfarin. Over the population of 1.7 million members, the cost for all hemorrhage events within 7 days of a pharmacy claim for warfarin was $\$ 0.40$ PMPM.
$\mathrm{R}$ esearch on medical errors has highlighted the prevalence of potential treatment-caused injuries in the United States. ${ }^{1.4}$ These medical errors can include drug-drug and drug-disease interactions. These interactions can result from proximal causes such as inattention by practitioners, lack of prescriber knowledge regarding the drugs, and lack of knowledge regarding the patient's drug history when drugs that interact are prescribed. ${ }^{5,6}$ Often, system errors such as defects in drug or patient knowledge dissemination can be identified that lead to these proximal causes. ${ }^{6}$

Warfarin, a medication that inhibits the synthesis of clotting factors, is the most commonly used oral anticoagulant today. ${ }^{7-9}$ Warfarin acts by interfering with hepatic synthesis of vitamin K-dependent clotting factors (II, VII, IX, and X) , $7,8,10,11^{-1}$ Physicians use warfarin for the treatment and prevention of venous thromboembolic disorders and the prevention of thromboembolic complications in patients with atrial fibrillation, valvular heart diseases, mechanical and bioprosthetic heart valves, and implanted artificial joints., ${ }^{9,12,13}$

Risks are associated with the use of warfarin, however. The main hazard associated with warfarin therapy is the risk of

CONCLUSIONS: Only 2 of 5 combinations of warfarin with drugs in this study were found to be associated with a higher prevalence of hemorrhage compared with warfarin use alone. The absolute prevalence of hemorrhage in users of warfarin and metronidazole was $22.7 \%$ and $17.2 \%$ for warfarin and cephalosporins, respectively, versus $14.2 \%$ in users of warfarin alone. The prevalence of hemorrhage for concomitant use of warfarin and NSAIDs/COX-2 inhibitors, amiodarone, or fibric acid derivatives such as fenofibrate was not greater than for warfarin alone. Liver disease or HF in warfarin users was associated with a significant increase in the likelihood of hemorrhage.

KEYWORDS: Patient safety, Warfarin

J Manag Care Pharm. 2006;12(8):640-48

Note: An editorial on the subject of this article appears on pages 686-87 of this issue.

\section{Authors}

KUI ZHANG, MD, is a manager and CHRISTOPHER YOUNG, PhD, is a director, Department of Research and Development, and JAN BERGER, MD, is chief clinical officer, CaremarkRx, Hunt Valley, Maryland.

AUTHOR CORRESPONDENCE: Kui Zhang, MD, Manager, Department of Research and Development, CaremarkRx, 11311 McCormick Rd. Hunt Valley, MD 21031. Tel: (410) 785-3349; Fax: (410) 785-8140; E-mail:kui.zhang@caremark.com

Copyright $\odot$ 2006, Academy of Managed Care Pharmacy. All rights reserved. 
hemorrhage. ${ }^{7,14}$ Hemorrhage is a concern for warfarin monotherapy and for warfarin used concomitant with other drugs and in the presence of certain diseases. Of particular concern are warfarin users with heart failure (HF) who subsequently suffer from hepatic dysfunction and are at increased risk of hemorrhage. ${ }^{15-17}$ Gurwitz et al. found that hemorrhage is the most common type of preventable adverse drug event among older persons in an ambulatory clinical setting. ${ }^{18}$ Landefeld and Beyth found that the average annual frequencies of fatal, major, and major or minor bleeding during warfarin therapy were 0.6\%,3.0\%, and $9.6 \%$, respectively. ${ }^{19}$ These frequencies are approximately 5 times those expected without warfarin therapy. ${ }^{20}$ Individuals who use warfarin either concomitant with certain drugs, such as mifepristone, antiplatelet medications, aspirin, certain fibric acid derivatives, or metronidazole, or who are diagnosed with certain conditions, including liver disease, active bleeding, recent trauma, or blood dyscrasias, are at increased risk of hemorrhage..$^{7,2,20}$

While the potential dangers of warfarin drug-drug and drugdisease interactions and the prevalence of concomitant use of warfarin with drugs that may result in a drug-drug and drugdisease interaction are known, less is known about the prevalence of clinical consequences and the cost of these drug-drug and drug-disease interactions. Evidence of clinical and economic consequences of drug-drug and drug-disease interactions may help quantify the need for additional education and/or other interventions. In this study, we used administrative medical and pharmacy claims data to evaluate the relative risk of hemorrhage in individuals taking warfarin concomitant with other drug therapy known to be associated with drug interactions or with diagnosed liver disease, compared with the use of warfarin alone. The working hypothesis of this study is that patients using warfarin concomitant with selected drugs and diseases (see Methods) have a greater relative risk of hemorrhage than do patients taking warfarin alone.

\section{Methods}

This analysis was conducted from the perspectives of the health plan and payer to provide information on the incidence of drugdrug and drug-disease interactions and of related adverse events. In this way, the information created in this study focuses not on the member's risk of hemorrhage but on the overall clinical and economic costs that a health plan payer bears as a consequence of drug-drug and drug-disease interaction. Benefits eligibility, which ensures that all information for a study subject is available for examination, does not allow for estimates of overall incidence of drug-drug and drug-disease interactions in a population. In an eligibility-controlled analysis, members without a full year of eligibility because of death or termination of benefits or for some other reason would be dropped from the analysis.

Therefore, rather than conducting a retrospective longitudinal analysis of individuals, tracking their use of medications after their first diagnosis of hemorrhage, we chose to analyze 1 calendar
TABLE 1) Sample Selection

\begin{tabular}{l|c|c}
\hline Inclusion Criteria & $\begin{array}{c}\text { No. of } \\
\text { Members } \\
\text { Who Did Not } \\
\text { Meet Criteria }\end{array}$ & $\begin{array}{c}\text { No. (\%) of } \\
\text { Members } \\
\text { Who Met } \\
\text { Criteria }\end{array}$ \\
\hline $\begin{array}{l}\text { Total members in health plans with } \\
\text { medical and pharmacy claims* }\end{array}$ & $1,701,724$ (100) \\
\hline $\begin{array}{l}\text { Patients with at least 1 pharmacy } \\
\text { claim for warfarin for the period } \\
\text { from October 1, 2003, through } \\
\text { September 30, 2004 }\end{array}$ & & 17,895 (1.1) \\
\hline
\end{tabular}

* Continuous eligibility was not required.

year of administrative claims data. This cohort study sample of combined deidentified medical and pharmacy claims data was drawn from 1.7 million health plan members for whom both medical and prescription data were available to Caremark Rx, a pharmacy benefits manager (PBM). This PBM provides services to a subset of these plans that require the health plans to provide medical claims data. The database of pharmacy and medical claims represented approximately 1.7 million individuals who were eligible for pharmacy and medical benefits at some time during the period under study (October 1, 2003, to September 30, 2004). To be included in the study, an individual must have been a member of a health plan that provided both medical and pharmacy claims data, must have received at least 1 pharmacy claim for warfarin during the study period, and must have been younger than 100 years. Table 1 describes the selection of the final study sample of 17,895 members who used warfarin during the year.

We followed 3 sets of events over time in this analysis: (1) the receipt of 2 pharmaceuticals or a pharmaceutical and a diagnosis that might result in a drug-drug or drug-disease interaction, (2) the diagnosis of hemorrhage within 1 week after the drug-drug or drug-disease interaction, and (3) the paid (plan) costs of hemorrhage that occurred after the drug-drug or drugdisease interaction through the end of the calendar year. Detailed definitions and descriptions of the selection process for drugs and diseases under study and of each of these outcomes follow below.

The primary source we used to identify potential warfarindrug and warfarin-disease interactions was the book Pharmacology, ${ }^{7}$ From this volume, we obtained a list of warfarin interactions from the section on warfarin (pp. 321, 322). To supplement this source, we used computer searches of medscape.com and google.com of the phrase "interactions of warfarin with drugs." From this list, we considered for study drugs that potentiate the anticoagulant effect of warfarin and that have one of the following characteristics: (1) inhibit hepatic drug metabolism (cimetidine, imipramine, co-trimoxazole, chloramphenicol, ciprofloxacin, metronidazole, and amiodarone); 


\begin{tabular}{ccccc}
\hline TABLE 2 & ICD-9 Codes $^{21}$ Used to \\
& Define Hemorrhaging \\
\hline $078.6 \mathrm{x}$ & $246.3 \mathrm{x}$ & $252.8 \mathrm{x}$ & $255.4 \mathrm{x}$ \\
262.81 & $285.1 \mathrm{x}$ & $286.5 \mathrm{x}$ & $286.6 \mathrm{x}$ & $286.9 \mathrm{x}$ \\
$287.3 \mathrm{x}$ & $287.4 \mathrm{x}$ & $287.8 \mathrm{x}$ & $287.9 \mathrm{x}$ & \\
360.43 & 362.43 & 362.81 & 363.61 & \\
363.62 & 363.72 & 364.41 & & \\
372.72 & 374.81 & 376.32 & 377.42 & 379.23 \\
$423.0 \mathrm{x}$ & $430 . \mathrm{xx}$ & $431 . \mathrm{xx}$ & $432 . \mathrm{xx}$ & $448.9 \mathrm{x}$ \\
$456.0 \mathrm{x}$ & $459.0 \mathrm{x}$ & $523.8 \mathrm{x}$ & $530.7 \mathrm{x}$ & 530.82 \\
$531.0 \mathrm{x}$ & $531.2 \mathrm{x}$ & $531.4 \mathrm{x}$ & $531.6 \mathrm{x}$ & $532.0 \mathrm{x}$ \\
$532.2 \mathrm{x}$ & $532.4 \mathrm{x}$ & $532.6 \mathrm{x}$ & $533.0 \mathrm{x}$ & $533.2 \mathrm{x}$ \\
$533.4 \mathrm{x}$ & $533.6 \mathrm{x}$ & $534.0 \mathrm{x}$ & $534.2 \mathrm{x}$ & $534.4 \mathrm{x}$ \\
$534.6 \mathrm{x}$ & 535.01 & 535.11 & 535.21 & 535.31 \\
535.41 & 535.51 & 535.61 & 537.83 & 562.02 \\
562.03 & 562.12 & 562.13 & 568.81 & $569.3 \mathrm{x}$ \\
569.85 & 569.86 & $578.9 \mathrm{x}$ & $578 . \mathrm{xx}$ & 593.81 \\
$596.7 \mathrm{x}$ & $596.8 \mathrm{x}$ & $599.7 \mathrm{x}$ & $602.1 \mathrm{x}$ & 607.82 \\
608.83 & $620.1 \mathrm{x}$ & $620.8 \mathrm{x}$ & $621.4 \mathrm{x}$ & $622.8 \mathrm{x}$ \\
$623.8 \mathrm{x}$ & $626.2 \mathrm{x}$ & $626.3 \mathrm{x}$ & $626.4 \mathrm{x}$ & $626.5 \mathrm{x}$ \\
$626.6 \mathrm{x}$ & $626.7 \mathrm{x}$ & $626.8 \mathrm{x}$ & $626.9 \mathrm{x}$ & $627.0 \mathrm{x}$ \\
$627.1 \mathrm{x}$ & $627.4 \mathrm{x}$ & $640 . \mathrm{xx}$ & $641.2 \mathrm{x}$ & $641.9 \mathrm{x}$ \\
$666.1 \mathrm{x}$ & 719.10 & 719.11 & 719.12 & 719.13 \\
719.14 & 719.15 & 719.16 & 719.17 & 719.18 \\
719.19 & $772.4 \mathrm{x}$ & $782.7 \mathrm{x}$ & $784.7 \mathrm{x}$ & $784.8 \mathrm{x}$ \\
$786.3 \mathrm{x}$ & $958.2 \mathrm{x}$ & $958.2 \mathrm{x}$ & 997.02 & 998.11 \\
\hline
\end{tabular}

ICD-9-CM=International Classification of Diseases, Ninth Revision,

Clinical Modification.

(2) inhibit platelet function (nonsteroidal anti-inflammatory drugs [NSAIDs], moxalactam, carbenicillin, and aspirin); (3) displace warfarin from binding sites on plasma albumin (some NSAIDs and chloral hydrate); (4) inhibit production of vitamin K (oral cephalosporins); (5) decrease the availability of vitamin K (sulfonamides); or (6) induce hepatic P450 enzymes (barbiturates, carbamazepine, griseofulvin, and rifampin). All these drugs will increase the degradation of warfarin. Heparin, which is an injectable anticoagulant, was considered for our study. Using this method, the authors endeavored to define a complete list of potential warfarin drug-drug and drug-disease interactions for study.

From those classes of drugs, we selected the following drugs and drug classes for study for which we had a pharmacy claim: NSAIDs, barbiturates, heparin, cimetidine, ciprofloxacin, metronidazole, carbamazepine, imipramine, amiodarone, cephalosporins, chloramphenicol, griseofulvin, rifampin, moxalactam, and carbenicillin. Of those drugs, the following had a prevalence of less than $1 \%$ and were too rare to be evaluated with traditional statistical methods: chloramphenicol, griseofulvin, rifampin, moxalactam, carbenicillin, barbiturates, heparin, cimetidine, ciprofloxacin, carbamazepine, and imipramine. Of these, carbamazepine had the greatest count of members, with 117 utilizers. Again, because concomitant use of 2 drugs with a potential drug-drug and drug-disease interaction concomitant with warfarin was uncommon, statistical evaluation was not possible for multiple, potentially interacting drugs.

We considered 3 medical conditions for analysis: liver disease, $\mathrm{HF}$, and thyrotoxicosis. ${ }^{8}$ Of those conditions, HF and liver disease occurred often enough in the study population to allow the use of statistical methods to evaluate the risk of hemorrhage.

Using these clinical and empirical criteria, warfarin users with a potential drug-drug and drug-disease interaction were identified and grouped for study using the following criteria: a diagnosis of liver disease (International Classification of Diseases, Ninth Revision, Clinical Modification, [ICD-9-CM] of 570.xx, 571.xx, 572.xx, or 573.xx) or HF (ICD-9-CM) of $428.0,428.22,428.23,428.32,428.33,428.42$, or 428.43) or who received a pharmacy claim for one of the following drugs or drug classes: NSAIDs (including cyclooxygenase-2 [COX-2] inhibitors), metronidazole, amiodarone, cephalosporins, and fibric acid derivatives.

A member with a potential drug-drug interaction was defined as an individual who had pharmacy claims in the database for 1 of these drugs and warfarin with at least 1 day of overlap in days supply of the 2 drugs. Members were not differentiated on the basis of the number of days of overlap. A member with a potential drug-disease interaction was defined as a member recently diagnosed with liver disease or HF. The criterion was selected arbitrarily as the presence of a diagnosis code within 3 weeks before a member filled a warfarin pharmacy claim. Hemorrhage was defined as the presence of a diagnosis code (Table 2) on a medical or hospital claim for a member who received a warfarin fill in the previous 7 calendar days. As noted in the footnote to Table 3, individuals who received warfarin through mail order would have a smaller number of "windows" during which we would count hemorrhaging. Following a conservative approach to estimation, we have not attempted to account for this difference by adding days to mail- order claims. Therefore, the cohort was defined as the group of individuals with a potential drug-drug and drug-disease interaction who, within 7 calendar days, experienced hemorrhage. This episode of hemorrhage was assumed to be related to the drug-drug and drug-disease interaction.

We evaluated the rate of hemorrhage in a comparison group of individuals who received warfarin therapy but no interacting pharmaceutical therapy or medical condition. The relative risk of hemorrhage was evaluated by comparing the rate of hemorrhage in those cohorts to the rate of hemorrhage in members who used only warfarin and who were not diagnosed with either liver disease or HF.

Direct medical costs were estimated using the total amount paid for a procedure or service after negotiated provider discounts and subtraction of patient copayment and deductibles for all records with a diagnosis of hemorrhage subsequent to the first instance of a drug-drug and drug-disease interaction. Included in these costs are inpatient hospital stays, outpatient hospital visits, emergency room visits, and lab tests. We did not 
attempt to weight costs based on the placement of the ICD-9$\mathrm{CM}$ code in the primary, secondary, or tertiary claim fields on the medical or hospital claim. However, only costs for medical and hospital claims with an ICD-9-CM code for hemorrhage were used. Costs to the health plans were calculated in 2 ways. One, per-member-per-month (PMPM) costs were defined as total dollars paid for claims for warfarin users with a diagnosis of hemorrhage divided by an estimated average member-month count (the total number of 1,701,724 members in the health plan during that year multiplied by 12). Two, per-patient-per-year (PPPY) costs for each drug-drug and drug-disease interaction were defined as the total costs to the plan associated with that drug-drug and drug-disease interaction divided by the total number of patients who had that particular drug-drug and drug-disease interaction during the study year.

Factors used as covariates in the regression of the likelihood of hemorrhage included member age (as of January 1, 2004), gender, average dose of warfarin in the study year, the medical specialty of the first prescriber for the first warfarin claim, the number of different prescribing physicians for the patient for any medication, a diagnosis for HF during that same time period (ICD-9-CM codes of 428.0, 428.22, 428.23, 428.32, 428.33, $428.42,428.43)$, and days of 2004 warfarin therapy. Physicians were identified using the Drug Enforcement Administration (DEA) numbers listed on the pharmacy claims. Because the same physician sometimes has 2 DEA numbers for 2 different medical practice locations, the number of prescribers tends to have an upward bias. The number of warfarin-prescribing DEA numbers in a year was categorized into 3 groups of 1, 2-3, or 4 or more. Physician specialty of the first provider of warfarin was categorized into 3 groups: cardiovascular, primary practitioner (family practitioner, general practitioner, internal medicine), and other physician specialties (Table 3).

To evaluate the dose of warfarin, we used the formula: dose = (strength $\mathrm{x}$ quantity)/days supply entered by the pharmacist. We averaged the doses of every individual for the study period and divided the members into 3 groups: (1) less than or equal to $5 \mathrm{mg} /$ day, (2) between $5 \mathrm{mg}$ /day and $7.5 \mathrm{mg} /$ day, and (3) greater than $7.5 \mathrm{mg} /$ day. The length of warfarin therapy was defined as the sum of the days supply of warfarin during the study year for every patient. For the last prescription during the year, if the fill date plus days supply was greater than the remaining days in the year, then the days supply was equal to the end date of the year minus the last prescription date. We categorized length of warfarin therapy into 3 groups: (1) less than or equal to 120 days, (2) between 121 days and 180 days, and (3) greater than 180 days. This variable is interpreted primarily as a proxy for exposure to warfarin therapy. Also, this variable may act as a proxy for eligibility. For this reason, we do not attempt to draw substantive conclusions based on this variable.

The data manipulation and statistical analyses were conducted in the SAS 8.2 system. ${ }^{21}$ Univariate statistics were used to

\section{TABLE 3 Description of Study Sample of Warfarin Users $(n=17,895)^{\star}$}

\begin{tabular}{|c|c|}
\hline Variable & Study Sample (No.) \\
\hline $\begin{array}{l}\text { Age and gender } \\
\text { Female, } \mathrm{n}(\%) \\
\text { Age in years, mean }[\mathrm{SD}]\end{array}$ & $\begin{array}{ll}9,067 & (50.6) \\
64.29 & {[14.6]}\end{array}$ \\
\hline $\begin{array}{l}\text { Warfarin dose and length of therapy } \\
\text { Warfarin dose in mgs } \dagger \text {, mean [SD] } \\
\text { Less than } 120 \text { days of warfarin therapy, n (\%) } \\
121-180 \text { days of warfarin therapy, } \mathrm{n}(\%) \\
181+\text { days of warfarin therapy, n (\%) }\end{array}$ & $\begin{array}{rr}6.18 & {[4.6]} \\
7,209 & (40.3) \\
2,518 & (14.1) \\
8,168 & (45.7)\end{array}$ \\
\hline $\begin{array}{l}\text { Prescriber numbers and medical specialty } \\
\text { Unique prescriber numbers, mean [SD] } \\
\text { Primary practitioner, } \mathrm{n}(\%) \\
\text { Cardiovascular specialty, } \mathrm{n}(\%) \\
\text { Other specialty, } \mathrm{n}(\%) \\
\text { Missing specialty, } \mathrm{n}(\%)\end{array}$ & $\begin{aligned} 4.22 & {[2.6] } \\
9,305 & (52.0) \\
3,564 & (19.9) \\
2,245 & (12.6) \\
2,781 & (15.5)\end{aligned}$ \\
\hline $\begin{array}{l}\text { Medical diagnoses for hemorrhage or heart failure } \\
\text { Hemorrhage } \neq, \mathrm{n}(\%) \\
\text { Heart failure, } \mathrm{n}(\%) \\
\text { Liver disease, } \mathrm{n}(\%)\end{array}$ & $\begin{aligned} 2,634 & (14.7) \\
1,875 & (10.5) \\
315 & (1.8)\end{aligned}$ \\
\hline $\begin{array}{l}\text { Most frequent hemorrhage diagnosis codes, } \mathrm{n}(\%) \\
\text { Hemorrhagic disorder due to circulating } \\
\text { anticoagulants (ICD-9-CM=286.5) } \\
\text { Hemorrhage of gastrointestinal tract, } \\
\text { unspecified (ICD-9-CM=578.9) } \\
\text { Hemorrhage of rectum and anus (ICD-9-CM=569.3) } \\
\text { Hemorrhage from nose, nosebleed (ICD-9-CM=784.7) } \\
\text { Hemoptysis (cough with hemorrhage, pulmonary } \\
\text { hemorrhage NOS, (ICD-9-CM=786.3) }\end{array}$ & $\begin{array}{l}640(2.6) \\
295(1.7) \\
223(1.3) \\
151(0.8) \\
93(0.5)\end{array}$ \\
\hline
\end{tabular}

* Fill date for pharmacy claims from October 1, 2003, to September 30, 2004.

† The distribution of warfarin pharmacy claims by strength: $12,710(11.9 \%) 1 \mathrm{mg}$, 11,537 (10.8\%) $2 \mathrm{mg}, 8,649$ (8.1\%) $2.5 \mathrm{mg}, 6,671$ (6.3\%) $3 \mathrm{mg}, 8,993$ (8.4\%) $4 \mathrm{mg}, 47,290$ (44.3\%) $5 \mathrm{mg}, 3,276$ (3.1\%) $6 \mathrm{mg}, 4,037$ (3.8\%) $7.5 \mathrm{mg}, 3,514$ (3.2\%) $10.0 \mathrm{mg}$.

\# Hemorrhage was defined by more than 100 ICD-9-CM codes (see Table 2). Mail-order prescriptions for a larger days supply of warfarin, typically 90 days, would result in a reduction in the opportunity to pair the hemorrhage diagnosis in the 7-day period; i.e., mail-order warfarin claims may result in an underestimate of the number of bleeding episodes associated with warfarin use as defined by the criteria in the present study.

ICD-9-CM=International Classification of Diseases, Ninth Revision, Clinical Modification; NOS=not otherwise specified.

describe the distribution of the study variables and the frequencies of the drug-drug and drug-disease interaction. Bivariate relationships were evaluated with either chi-square or $t$ tests as appropriate. Logistic regression was used to evaluate the relative risk of hemorrhage in users of warfarin monotherapy and of warfarin users with drug-drug and drug-disease interactions. The comparison group in the logistic regression comprised the members who received warfarin therapy but no other drug therapy. Therefore, the odds ratios (ORs) produced were estimates of the relative risk of hemorrhage when taking warfarin concomitant with selected drugs and diseases. 
TABLE 4 Prevalence of Hemorrhage* in Warfarin Users

\begin{tabular}{|c|c|c|c|c|c|}
\hline Drug & Patients & $\%$ Warfarin Users & $\begin{array}{l}\% \text { (n) Warfarin Users } \\
\text { With Hemorrhage* }\end{array}$ & Age Mean [SD] & $\%$ Female \\
\hline Warfarin-liver disease & 315 & 1.8 & $26.4(83)$ & $59.43[13.3]$ & 55.6 \\
\hline Warfarin-metronidazole & 779 & 4.4 & $22.7(177)$ & $63.61[14.5]$ & 64.3 \\
\hline Warfarin-cephalosporins & 3,385 & 18.9 & $17.2(583)$ & $64.94[15.1]$ & 54.1 \\
\hline Warfarin-amiodarone & 1,260 & 7.0 & $14.8(186)$ & $68.37[11.6]$ & 38.8 \\
\hline Warfarin-heart failure & 1,875 & 10.5 & $14.7(388)$ & $71.69[13.2]$ & 49.2 \\
\hline Warfarin-NSAIDs & 4,906 & 27.4 & $14.3(700)$ & $64.73[13.4]$ & 48.3 \\
\hline Warfarin only & 9,147 & 51.1 & $14.2(1,289)$ & $63.57[15.1]$ & 47.5 \\
\hline $\begin{array}{l}\text { Warfarin-fibric acid } \\
\text { derivatives }\end{array}$ & 761 & 4.3 & $13.1(100)$ & $64.06[11.1]$ & 33.9 \\
\hline Total & 17,895 & 100.0 & $14.7(2,634)$ & $64.29[14.6]$ & 50.7 \\
\hline
\end{tabular}

Note: Some members had more than 1 drug-drug or drug-disease interaction; therefore, the number of potential drug-drug or drug-disease interactions exceeds the reported total.

* Hemorrhage was defined from the presence of at least 1 of more than 100 ICD-9-CM codes (see Table 2).

ICD-9-CM=International Classification of Diseases, Ninth Revision, Clinical Modification; NSAIDs=nonsteroidal anti-inflammatory drugs.

\section{Results}

Of the 1.7 million members eligible for drug and medical benefits during the study period (see below), 17,895 members filled at least 1 pharmacy claim for warfarin and were selected for study (Table 3). Warfarin users averaged age 64.3 years with a standard deviation of 14.6 years. The study patients received prescriptions from an average of 4.2 unique DEA numbers, although most warfarin users (73\%) received all of their prescriptions from 5 or fewer prescribers.

Of the 17,895 members who used warfarin during the study year, 2,634 (14.7\%) were diagnosed with hemorrhage subsequent to filling a prescription for warfarin. The most common hemorrhage diagnoses by ICD-9-CM code were hemorrhagic disorder due to circulating anticoagulants (286.5), hemorrhage of gastrointestinal tract, unspecified, (578.9) hemorrhage of rectum and anus (569.3), hemorrhage from nose, nosebleed (784.7), hemoptysis (cough with hemorrhage, and pulmonary hemorrhage not otherwise specified, (786.3) (Table 3). Of the warfarin users, $1,260(7.0 \%)$ concomitantly received prescriptions for amiodarone, 4,906 (27.4\%) for an NSAID/COX-2, 3,385 (18.9\%) for cephalosporin, 779 (4.4\%) for metronidazole, and 761 (4.3\%) for fibric acid derivative. Of the NSAID/COX-2 drug-drug or drug-disease interactions, 3,114 (63.5\%) were associated with a COX-2 inhibitor, 1,340 (26.6\%) with a nonselective NSAID, and 452 (9.2\%) with both. Of warfarin users, 315 (1.8\%) had a diagnosis of liver disease and 1,875 (10.5\%) had a diagnosis of HF. Table 4 reports the average age and gender for each drug-drug or drug-disease interaction pair.

The prevalence of hemorrhage, defined as a binary variable, was regressed on indicators for each of these drug-drug or drugdisease interactions as well as member age, gender, average warfarin dose, number of days of warfarin therapy, number of unique prescribers, a diagnosis of HF, and physician specialty of the first prescriber of warfarin during the study year. The result of logistic regression is presented in Table 5. Liver disease in warfarin users was associated with a significant increase in the likelihood of hemorrhage when compared with warfarin monotherapy users $(P<0.05)$. Patients who were taking warfarin and who had a diagnosis of HF were 1.559 times as likely to be diagnosed subsequently with hemorrhage. Warfarin used concomitant with cephalosporins or metronidazole also was associated with significantly increased likelihood of hemorrhage over warfarin use alone $(P<0.05)$. Members who received prescriptions from multiple prescribers were at higher risk of hemorrhage $(P<0.05)$. Compared with patients who had their first prescription for warfarin written by a cardiologist, patients who received their first prescription for warfarin from any other specialist were associated with a higher risk of hemorrhage $(P<0.05)$. Women were somewhat more likely to hemorrhage than men $(P<0.05)$, and younger members were somewhat more likely to be diagnosed with hemorrhage $(P<0.05)$. The risk of hemorrhage increased with the duration of warfarin use in days. The average daily dose of warfarin and concomitant use of amiodarone and fibric acid derivatives were not significantly related to the hemorrhage rate. NSAID/COX-2 use was negatively related to the likelihood of hemorrhage, although marginally so.

Overall, a cost of $\$ 0.40$ PMPM was associated with hemorrhage events recorded in medical or hospital claims within 7 days of receipt of a warfarin fill. When disaggregated by the associated drug-drug or drug-disease interaction, the PMPM cost varied considerably according to the volume of the patients with each interaction. The PMPM cost associated with hemor- 
rhage was highest for the group of warfarin-NSAID/COX-2 drug-drug or drug-disease interactions $(\$ 0.16)$, warfarin users with no drug-drug or drug-disease interactions (\$0.13), and warfarin-cephalosporins drug-drug or drug-disease interactions (\$0.09). The PMPM costs for the other drug-drug or drug-disease interactions in this analysis ranged from $\$ 0.02$ for liver disease to $\$ 0.05$ for fibric acid derivatives (Table 6).

The costs are ranked differently when the denominator used is the number of patients who have been identified with each drug-drug or drug-disease interaction. Although the PMPM for warfarin-liver disease drug-drug or drug-disease interactions is relatively low $(\$ 0.02)$, the PPPY is relatively high $(\$ 1,135)$. The PPPY values for the other drug-drug or drug-disease interactions found to be statistically significant were $\$ 896$ for warfarin-metronidazole, $\$ 663$ for warfarin in HF, and $\$ 569$ for warfarincephalosporins. For individuals who used only warfarin, the average PPPY was $\$ 293$, the lowest of any of the PPPY values.

\section{Discussion}

Over the last several years, there has been increasing focus on avoidable medical errors, especially avoidable medication errors. Although warfarin is a drug that has been on the market for many years and has significant use in the medical community, it remains a drug that can put a patient at risk for an adverse drug event.

Of the warfarin drug and disease interactions in the study, concomitant use of 5 drug categories occurred with a sufficient statistical frequency to evaluate the risk of hemorrhage. In addition, we evaluated comorbid heart disease and liver disease. Of the 5 drug categories, cephalosporins and metronidazole increased the likelihood of hemorrhage. Both cephalosporins and metronidazole are antibiotics, suggesting short-term use. Cephalosporins and metronidazole both have a relatively high incidence of use with warfarin and are associated with an increase in the likelihood of hemorrhage. This would suggest that greater care must be taken by clinicians who dispense these medications. Increased member-physician communication and education as well as programs such as pharmacy messaging, academic detailing of physicians by pharmacists, and electronic prescribing may help prevent this type of drug-drug or drugdisease interaction. ${ }^{22}$ In contrast, despite the high costs associated with warfarin-NSAID/COX-2 drug-drug or drug-disease interactions, these drug-drug or drug-disease interactions were negatively related to the likelihood of hemorrhage, although marginally so, as stated above. In part, this may be because many NSAIDs are now available over the counter, resulting in underreporting of the use of NSAIDs and therefore of warfarinNSAID/COX-2 drug-drug or drug-disease interactions.

Members with liver disease also faced an increased likelihood of hemorrhage. Similarly, members with HF were more likely to also be diagnosed with hemorrhage. Because it appears that some members with HF have an increased responsiveness

\begin{tabular}{|c|c|c|c|}
\hline \multirow[b]{2}{*}{ Variable } & \multirow[b]{2}{*}{ Odds Ratio $\dagger$} & \multicolumn{2}{|c|}{0.05 Wald Confidence Interval } \\
\hline & & Low & High \\
\hline Female vs. male & $1.149 \dagger$ & 1.053 & 1.253 \\
\hline Decrease in age of 1 year & $1.009 \dagger$ & 1.006 & 1.012 \\
\hline Heart failure & $1.559 \dagger$ & 1.373 & 1.770 \\
\hline Liver disease & $1.764 \dagger$ & 1.360 & 2.288 \\
\hline Cephalosporins & $1.157 \dagger$ & 1.043 & 1.285 \\
\hline Metronidazole & $1.578^{\dagger}$ & 1.321 & 1.886 \\
\hline Amiodarone & 0.980 & 0.827 & 1.162 \\
\hline Fibric acid derivatives & 0.823 & 0.660 & 1.025 \\
\hline NSAIDs/COX-2s & $0.904 \dagger$ & 0.820 & 0.997 \\
\hline \multicolumn{4}{|l|}{ Average dose of warfarin } \\
\hline$\leq 5 \mathrm{mg}$ & 1.000 & & \\
\hline $5 \mathrm{mg}$ to $7.5 \mathrm{mg}$ & 1.077 & 0.966 & 1.201 \\
\hline More than $7.5 \mathrm{mg}$ & 1.071 & 0.962 & 1.191 \\
\hline \multicolumn{4}{|l|}{ Days of warfarin therapy } \\
\hline$\leq 120$ days & 1.000 & & \\
\hline 120 to 180 days & $1.571 \dagger$ & 1.373 & 1.797 \\
\hline More than 180 days & $1.953 \dagger$ & 1.771 & 2.155 \\
\hline \multicolumn{4}{|l|}{$\begin{array}{l}\text { Number of unique } \\
\text { prescriber numbers }\end{array}$} \\
\hline 1 & 1.000 & & \\
\hline $2-3$ & $1.284 \dagger$ & 1.082 & 1.524 \\
\hline$\geq 4$ & $1.799 \dagger$ & 1.519 & 2.130 \\
\hline \multicolumn{4}{|l|}{ Prescriber specialty } \\
\hline Cardiovascular & 1.000 & & \\
\hline Primary care practitioner & $1.216 \dagger$ & 1.097 & 1.348 \\
\hline Other specialty & $1.303 \dagger$ & 1.117 & 1.521 \\
\hline \multicolumn{4}{|c|}{$\begin{array}{l}\text { Likelihood ratio }=441.29,17 \mathrm{df}, P \leq 0.001 . \\
* \text { Regression analysis. } \\
\dagger \text { Odds ratios are significant at } P<0.05 . \\
¥ \text { The medical specialty of the first prescriber of warfarin therapy. } \\
\text { COX-2 }=\text { cyclooxygenase- } 2 ; \text { NSAIDs }=\text { nonsteroidal anti-inflammatory drugs. }\end{array}$} \\
\hline
\end{tabular}

to oral anticoagulants, ${ }^{11}$ and because HF-induced hepatic congestion can cause hepatic dysfunction, practitioners may be faced with a patient who is being treated with warfarin and who has liver disease. The results of this study suggest that care must be taken when treating members with these 2 health problems.

The number of days of warfarin therapy was found to be positively related to the likelihood of hemorrhage. This study does not allow us to evaluate the reasons behind this finding. As noted in the Methods section, this variable may be, in part, a proxy for eligibility. It is possible that a member with longerterm warfarin therapy simply has more opportunities for drugdrug or drug-disease interactions that may result in adverse side effects. Further potential explanations for this may be that long- 


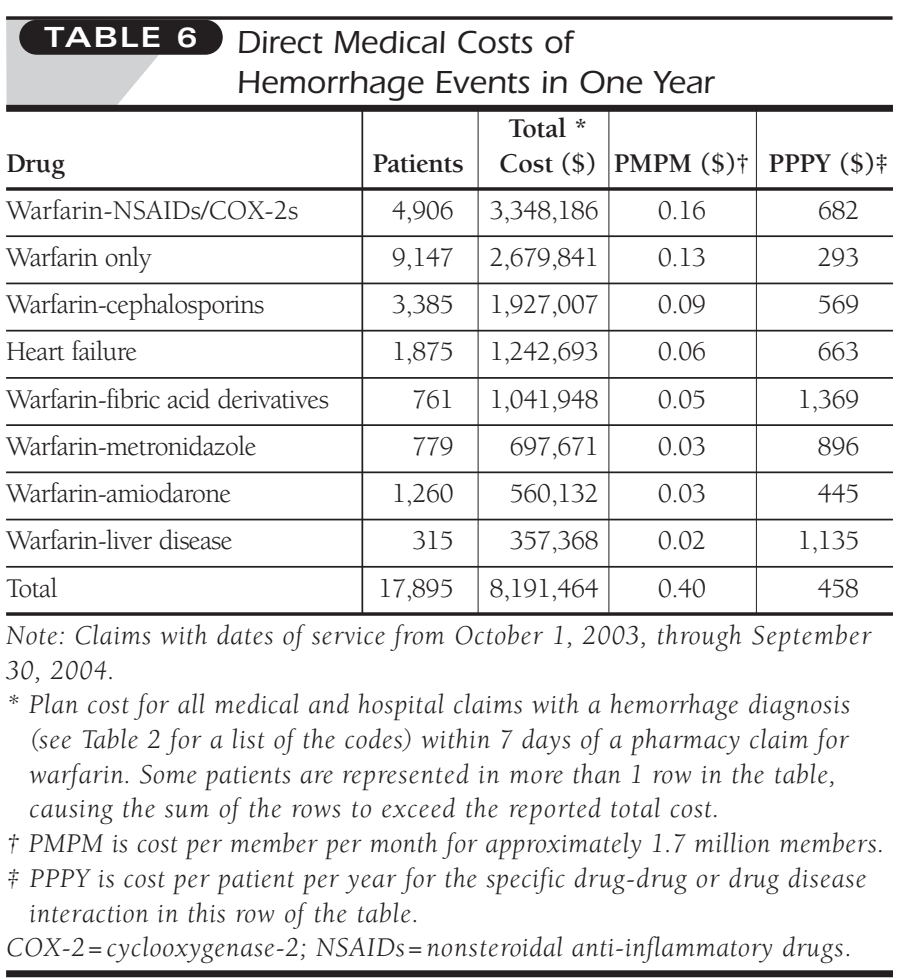

term use itself may be related to hemorrhage, or it may take longer for symptoms of some of the adverse events to become acute enough to warrant a visit to a physician. This finding suggests physicians' review of chronic warfarin use may help prevent adverse reactions. Warfarin use requires long-term monitoring. Members may not comply with testing, which may increase the frequency of hemorrhage.

Tools such as prospective drug utilization reviews (pDURs) were recently evaluated by Malone et al. with a nonrandom sample of 46 million Americans. In this study, they found that the pDUR employed by the PBM in the current study rejected between $19 \%$ and $46 \%$ of claims that may result in a drug-drug interaction, depending on the class of drugs. ${ }^{23}$ On one hand, these rates testify to the success of the pDUR program. On the other, many drugs with the potential for drug-drug interactions are prescribed despite the warnings. In their discussion of why these drug-drug interactions continue to occur, Malone et al. identified 1 factor as lack of physician awareness of drug-drug interactions. They cited a survey of physicians in the Southern California Veterans Affairs Healthcare System as properly identifying only $44 \%$ of drug-drug interactions ${ }^{24}$ as well as further evidence that physicians and pharmacists did not recognize many drug-drug interactions.

Compounding the problem of physician awareness may be the number of different practitioners who prescribe drugs for patients and the dispersion of medical and pharmacy records. ${ }^{25,26}$ We found that the likelihood of hemorrhage is greater for patients receiving prescriptions from a greater number of prescriber numbers. This suggests that programs to increase communication between practitioners also may help reduce adverse reactions to drug-drug interactions. The results obtained in this study, in which 2 out of 5 possible drug-drug interactions were associated with a statistically significant increased risk of hemorrhage compared with warfarin use alone, suggest that further research is needed to identify which of the many possible drug-drug interactions require focus for communication interventions with prescribers. Programs that give providers information on the complete prescription history of their patients, similar to the point-of-service (POS) drug utilization review (DUR) services that PBMs provide to pharmacies, may help to reduce drug-drug interactions. ${ }^{22,23}$ Other tools such as electronic prescribing and direct consultations with physicians should be used to reinforce contraindications and risks of drugdrug or drug-disease interactions when prescribing warfarin. Disease management programs focusing on HF should be engaged in monitoring appropriate warfarin prescribing.

The risk associated with the use of warfarin necessitates greater attention by physicians when initiating therapy and on an ongoing basis. Even with this increased focus by physicians, the risk of drug-drug or drug-disease interactions still exists because of the fragmentation found in health care delivery today. Due to the lack of transparency of care across all caregivers, organizations such as PBMs and managed care organizations will also have a role in this process. These organizations, by virtue of their aggregation of all claims associated with a patient, need to work with physicians to get them all the information necessary to make a clinically informed prescribing decision. This can be done through safety checks for all community or mail-service pharmacy prescriptions with feedback to the prescribing physician and through support of electronic prescribing.

The costs associated with drug-drug or drug-disease interactions seem to warrant attention. When calculated per member and per drug-drug or drug-disease interaction, costs associated with drug-drug or drug-disease interactions suggest that, in addition to reducing the risk of hemorrhage and further complications, a program to reduce drug-drug or drug-disease interactions could result in significant plan savings as well. Many drug-drug or drug-disease interactions are approved by physicians or pharmacists despite POS DUR alerts that notify pharmacists of potential drug-drug or drug-disease interactions at the time of claim adjudication. ${ }^{27}$

\section{Limitations}

One of the primary limitations of this study is that data on the international normalized ratio (INR) are not available. These data on the INR would allow researchers to better evaluate whether the anticoagulant therapy for these patients was within therapeutic range. Another limitation is that the combination of the large number of potential warfarin-drug interactions com- 
bined with the limited size of the dataset made it impossible to evaluate the impact of all potential warfarin drug interactions. Yet another limitation is that we did not control for disease severity in this study.

Perhaps foremost in this study, the relationship between warfarin use and hemorrhage events is merely a temporal one, and it is not possible to attribute directly the hemorrhage claims to the use of warfarin alone or in combination with disease or drugs known to interact with warfarin. It is also possible that the costs attributed to hemorrhage events are overstated since claims aggregation was based on having a hemorrhage diagnosis on any field on the medical or hospital claim, not necessarily being the primary diagnosis on the claim.

We could not control for the use of over-the-counter products, herbal products (e.g., garlic, ginkgo biloba), or food consumed by the study subjects that is known to interact with warfarin. The lack of data on over-the-counter drugs may have had an impact on the results for the relative risk of hemorrhage in patients who received both warfarin and prescription NSAID/COX-2 therapy. Several natural products contain substances that have coumarin, salicylate, or antiplatelet properties. A theoretical risk for potentiation of the pharmacologic activity of warfarin exists, therefore, when these herbs or food are taken with warfarin..$^{28}$ In addition, we did not distinguish hemorrhage by organ.

Another limitation is that the identification of drugs dispensed to inpatients is not available from administrative claims. Another consideration in the interpretation of these results is that only those bleeding events that resulted in visits to physicians or hospitals and were diagnosed as hemorrhages were considered in this analysis. Therefore, the nonsignificant results for some of the drug-drug or drug-disease interactions may mask problems that were not detected by physicians, not diagnosed, or not recorded as such. Further, the small incidence of some of the drug-drug or drug-disease interactions limited our ability to distinguish outcomes for many of the drug-drug or drug-disease interactions.

\section{Conclusions}

The analysis of administrative claims data confirms the observations from clinical trials and further quantifies the incidence of warfarin drug-drug or drug-disease interactions associated with hemorrhage events. The frequency of concomitant warfarin use with metronidazole was $4.4 \%$ and with oral cephalosporins, $18.9 \%$; $22.7 \%$ and $17.2 \%$, respectively, of this concomitant use was associated with at least 1 hemorrhage event. There was no higher risk of a hemorrhage event for the concomitant use of warfarin with NSAIDs, including COX-2 inhibitors, amiodarone, or fibric acid derivatives, compared with the use of warfarin alone, with absolute rates of hemorrhage in the range of $13.1 \%$ to $14.8 \%$ for these 3 drug-drug combinations versus a $14.2 \%$ prevalence of hemorrhage for use of warfarin alone. Patients diagnosed with liver disease or HF are more likely to experience a hemorrhage event while on warfarin therapy.

\section{DISCLOSURES}

No outside funding supported this research. Author Kui Zhang served as principal author of the study. Study concept and design were contributed by Zhang. Data collection was the work of Zhang and author Christopher Young; data interpretation was primarily the work of Zhang and Young, with input from author Jan Berger. Writing of the manuscript was primarily the work of Young, with input from Zhang; its revision was primarily the work of Young, with major input from Berger and input from Zhang. The authors disclose no potential bias or conflict of interest relating to this article.

\section{REFERENCES}

1. Brennan TA, Leape LL, Laird NM, et al. Incidence of adverse events and negligence in hospitalized patients. N Engl J Med. 1991;324:370-76.

2. Leape LL. Error in medicine. JAMA. 1994;272(23):1851-57.

3. Gandhi TK, Weingart SN, Borus J, et al. Adverse drug events in ambulatory care. N Engl J Med. 2003;348(16):1556-64.

4. Bates DW, Cullen DJ, Laird N, et al. Incidence of adverse drug events and potential adverse drug events. Implications for prevention. ADE Prevention Study Group. JAMA. 1995;274(1):29-34.

5. Leape MD LL. A systems analysis approach to medical error. J Eval Clin Pract. 1997;3:213-22

6. Leape LL, Bates DW, Cullen DJ, et al. Systems analysis of adverse drug events JAMA. 274(1):35-43.

7. Rang HP, Dale MM, Pitter JM, Moore PK. Pharmacology. 5th ed. Edinburgh, Scotland: Churchill Livingston; 2003:321-23.

8. Demirkan K, Stephens MA, Newman KP, Self TH. Response to warfarin and other oral anticoagulants: effects of disease states. South Med J. 2000;93(5): 448-55.

9. Hart A, Hopkins C, eds. International Classification of Diseases. 6th ed. ICD-9-CM. Vol. 1-3. Hyattsville, MD: National Center for Health Statistics: 2003.

10. Majerus PW, Broze GJ, Miletich JP, Tollefsen DM. Anticoagulant, thrombolytic, and antiplatelet drugs. In: Hardman JG, Limbird LE, Molinoff PB, Ruddon RW, Gilman AG, eds. Goodman and Gilman's the Pharmacological Basis of Therapeutics. 9th ed. New York, NY; McGraw-Hill; 1996:1341-60.

11. Hirsh J, Dalen JE, Anderson DR, et al. Oral anticoagulants: mechanism of action, clinical effectiveness, and optimal therapeutic range. Chest. 1998; 114(5 suppl):45S-69S.

12. Hirsh J, Dalen JE, Anderson DR, et al. Oral anticoagulants: mechanism of action, clinical effectiveness, and optimal therapeutic range. Chest. 2001; 119(1 suppl):8S-21S

13. Ridker PM, Goldhaber SZ, Danielson E, et al. Long-term, low-intensity warfarin therapy for the prevention of recurrent venous thromboembolism. N Engl J Med. 2003;348:1425-34.

14. Levine MN, Raskob G, Landefeld S, Kearon C. Hemorrhagic complications of anticoagulant treatment. Chest. 1998;114(5 suppl):511S-523S.

15. Donaldson GWK, Kavies SH, Darg A, et al. Coagulation factors in chronic liver disease. J Clin Pathol. 1969;22:199-204.

16. Gallus AS, Lucas CR, Hirsh J. Coagulation studies in patients with acute infectious hepatitis. Br J Haematol. 1972;22:761-71.

17. Koller F. Theory and experience behind the use of coagulation tests in diagnosis and prognosis of liver disease. Scand J Gastroenterol. 1973;8 (suppl 19):51-61.

18. Gurwitz JH, Field TS, Harrold LR, et al. Incidence and preventability of adverse drug events among older persons in the ambulatory setting. JAMA. 2003;289(9):1107-16.

19. Landefeld CS, Beyth RJ. Anticoagulant-related bleeding: clinical epidemiology, prediction, and prevention. Am J Med. 1993;95(3):315-28. 
20. Wells PS, Holbrook AM, Crowther NR, Hirsh J. Interactions of warfarin with drugs and food. Ann Intern Med. 1994;121:676-83.

21. SAS Institute Inc., Cary, NC 27516

22. Feldstein A, Smith D, Perrin N, et al. Reducing warfarin interactions: an interrupted time series evaluation. Arch Intern Med. 2006;166(9):1009-15.

23. Malone D, Hutchins D, Haupert H, et al. Assessment of potential drugdrug interactions with a prescription claims database. Am J Health Syst Pharm. 2005;62(19):1983-91.

24. Glassman PA, Simon B, Belperio P, et al. Improving recognition of drug interactions: benefits and barriers to using automated alerts. Med Care. 2002;40:1161-71.
25. Lau HS, Florax C, Porsius AJ, et al. The completeness of medication histories in hospital records of patients admitted to general internal medicine wards. Br J Clin Pharmacol. 2000;49:597-603

26. Sjahid SI, van der Linden PD, Stricker BH. Agreement between the pharmacy medication history and patient interview for cardiovascular drugs: the Rotterdam elderly study. Br J Clin Pharmacol. 1998;45:591-95.

27. Leape LL, Bates DW. Adverse drug events in ambulatory care. N Engl J Med. 2003;348(16):1556-64.

28. Heck AM, Dewitt BA, Lukes AL. Potential interactions between alternative therapies and warfarin. Am J Health Syst Pharm. 2000;57(13):1221-27. 